Lepr Rev (1980) 51, 285-294

SPECIAL ARTICLE

We are indebted to the Pan-American Health Organisation (PAMO).

Washington, USA, for permission to publish this article

\title{
Leprosy in the Americas region (AMRO)
}

\author{
DR CELIO PAULA MOTTA \\ Caracas, Venezuela
}

Background information for activities to be implemented with Sasakawa Memorial Foundation aid (Japanese shipbuilding industry funds).

\section{Introduction}

Leprosy is an imported endemia in the Americas. All evidence points out that the indigenous population never had the disease before the arrival of the settlers (Spanish, Portuguese, French and Dutch), and later African Negroes imported as slaves.

Several leprosy foci have developed in the last four centuries, always related to the migratory pattern of the settlers. The most important focus is the South American Amazon region, a recent one, since it was only populated and settled during the last quarter of the nineteenth century.

As a general pattern, the leprosy problem is of median size when compared with Asian or African foci. The geographical distribution of cases is not uniform. There is a trend towards concentration in well-defined foci, some with high prevalence rates $(20-30$ per 1,000$)$.

Until the 1950s it was estimated that most of the cases (about 70\%) came from the rural area (villages of less than 2,500 inhabitants or scattered population), but now the situation is inverse due to the phenomenon of 'fast urbanization' in several American countries.

Other important patterns of the disease are:

(a) With few exceptions, half of the detected cases are multibacillary (lepromatous and borderline).

(b) The percentage of detected cases in the group $0-14$ years is less than $15 \%$. 
Table 1. Leprosy cases on the active register by country, estimated number of patients, prevalence rates and cases under surveillance, 1976 or most recent year (American region)

\begin{tabular}{|c|c|c|c|c|c|c|c|}
\hline \multirow[b]{2}{*}{ Country or territory } & \multirow{2}{*}{$\begin{array}{r}\begin{array}{r}\text { Fstimated } \\
\text { population } \\
\text { (in } 1,000 \mathrm{~s})\end{array} \\
30 \text { June } 1976\end{array}$} & \multicolumn{2}{|c|}{ Registered cases } & \multicolumn{2}{|c|}{ Total estimated } & \multicolumn{2}{|c|}{$\begin{array}{l}\text { Cases under } \\
\text { surveillance }\end{array}$} \\
\hline & & Year & Number & Number & $\begin{array}{c}\text { Rate per } \\
1,000\end{array}$ & Number & $(\%)$ \\
\hline \multicolumn{8}{|l|}{ PAHO/WHO Area I } \\
\hline \multicolumn{8}{|l|}{ Countries } \\
\hline Venezuela & 11,632 & 1975 & 12,734 & $19,101(a)$ & 1.6 & 8,923 & 46.7 \\
\hline Surinam & 411 & 1973 & 2,311 & $4,044(b)$ & 9.8 & 2,311 & 57.2 \\
\hline Guyana & 774 & 1976 & 665 & $1,164(b)$ & 1.5 & 642 & 55.2 \\
\hline Trinidad \& Tobago & 1,070 & 1976 & 906 & $1,359(a)$ & 1.3 & 869 & 63.9 \\
\hline Barbados & 244 & 1975 & 33 & $66(c)$ & 0.3 & 33 & 50.0 \\
\hline Grenada & 96 & 1975 & 94 & . $282(\mathrm{~d})$ & 2.9 & 94 & 33.3 \\
\hline Jamaica & 2,008 & 1975 & 366 & 549(a) & 0.3 & 348 & 63.4 \\
\hline Bahamas & 197 & 1974 & 1 & $3(\mathrm{~d})$ & 0.0 & 1 & 33.3 \\
\hline \multicolumn{8}{|l|}{ British territories } \\
\hline St. Vincent & 96 & 1968 & 13 & $39(d)$ & 0.4 & 13 & 33.3 \\
\hline St. Lucia & 107 & 1973 & 204 & $408(c)$ & 3.8 & 204 & 50.0 \\
\hline Montserrat & 12 & 1975 & 2 & $6(d)$ & 0.5 & 2 & 33.3 \\
\hline Antigua & 70 & 1976 & 48 & $144(d)$ & 2.1 & 10 & 6.9 \\
\hline \multicolumn{8}{|l|}{ St Kitts-Nevis- } \\
\hline Anguilla & 65 & 1975 & 4 & $12(d)$ & 0.2 & 4 & 33.3 \\
\hline British Virgin Islands & 10 & $\ldots$ & $\cdots$ & $10(e)$ & 1.0 & $\ldots$ & $\cdots$ \\
\hline Dominica & 74 & 1975 & 11 & $33(d)$ & 0.5 & 11 & 33.3 \\
\hline Cayman Islands & 11 & $\ldots$ & $\ldots$ & $10(e)$ & 0.9 & $\ldots$ & $\ldots$ \\
\hline \multicolumn{8}{|l|}{ Turks \& Caicos } \\
\hline Islands & - & 1974 & ... & $10(\mathrm{e})$ & - & $\ldots$ & ... \\
\hline Bermuda & 55 & 1975 & 2 & $6(d)$ & 0.1 & 2 & 33.3 \\
\hline \multicolumn{8}{|l|}{ French territories } \\
\hline French Guiana & 58 & 1971 & 957 & $1,436(a)$ & 24.8 & 749 & 52.2 \\
\hline Guadeloupe & 349 & 1975 & 2,033 & $3,050(a)$ & 8.7 & 1,802 & 59.1 \\
\hline Martinique & 358 & 1973 & 2,180 & $3,270(a)$ & 9.1 & 1,204 & 36.8 \\
\hline \multicolumn{8}{|l|}{ Netherlands } \\
\hline Antilles & 238 & $\ldots$ & $\ldots$ & $20(\mathrm{e})$ & 0.1 & $\ldots$ & $\ldots$ \\
\hline Subtotal & 17,935 & & 22,564 & 35,012 & 1.9 & 17,222 & 49.1 \\
\hline \multicolumn{8}{|l|}{ PAHO/WHO Area II } \\
\hline Mexico & 58,118 & 1975 & 14,775 & $25,857(b)$ & 0.4 & 10,742 & 41.5 \\
\hline Cuba & 9,090 & 1975 & 4,554 & $6,831(a)$ & 0.8 & 4,417 & 64.7 \\
\hline Dominican Republic & 4,562 & 1976 & 3,739 & $6,544(b)$ & 1.4 & 3,349 & 51.2 \\
\hline Haiti & 5,414 & 1974 & 270 & $810(\mathrm{~d})$ & 0.2 & 94 & 11.6 \\
\hline Subtotal & 77,184 & & 23,338 & 40,042 & 0.5 & 18,602 & 46.5 \\
\hline \multicolumn{8}{|l|}{ PAHO/WHO Area III } \\
\hline Guatemala & 5,328 & 1977 & 186 & $558(d)$ & 0.1 & 72 & 12.9 \\
\hline El Salvador & 3,980 & 1975 & 1 & 300(e) & 0.1 & 1 & 0.3 \\
\hline Nicaragua & 2,084 & 1973 & 291 & $873(d)$ & 0.4 & 140 & 16.0 \\
\hline Costa Rica & 1,921 & 1976 & 444 & $777(b)$ & 0.4 & 375 & 48.3 \\
\hline Panama & 1,618 & 1975 & 167 & $251(\mathrm{a})$ & 0.2 & 167 & 66.5 \\
\hline Honduras & 2,933 & 1974 & 263 & $526(c)$ & 0.2 & 98 & 18.6 \\
\hline Belize & 136 & 1971 & 1 & $10(\mathrm{e})$ & 0.1 & 1 & 10.0 \\
\hline Subtotal & 18,000 & & 1,353 & 3,295 & 0.2 & 854 & 25.9 \\
\hline
\end{tabular}


PAHO/WHO Area IV

\begin{tabular}{|c|c|c|c|c|c|c|c|}
\hline Bolivia & 4,688 & 1976 & 1,705 & 5,629 & 1.2 & 1,107 & 19.7 \\
\hline Colombia & 22,807 & 1975 & 18,625 & $37,250(\mathrm{c})$ & 1.6 & 16,693 & 44.8 \\
\hline Ecuador & 6,951 & 1974 & 2,801 & $5,602(c)$ & 0.8 & 2,542 & 45.4 \\
\hline Peru & 15,383 & 1973 & 2,708 & $5,416(\mathrm{c})$ & 0.4 & 1,638 & $\underline{30.2}$ \\
\hline Subtotal & 49,829 & & 25,839 & 53,897 & 1.1 & 21,980 & 40.8 \\
\hline \multicolumn{8}{|c|}{ PAHO/WHO Area V } \\
\hline Brazil & 110,124 & 1976 & $\underline{150,840}$ & 242,273 & 2.2 & 91,984 & 38.0 \\
\hline Subtotal & 110,124 & & 150,840 & 242,273 & 2.2 & 91,984 & 38.0 \\
\hline \multicolumn{8}{|c|}{ PAHO/WHO Area VI } \\
\hline Argentina & 26,056 & 1967 & 9,627 & 14,852 & 0.57 & 6,122 & 41.2 \\
\hline Chile & 10,655 & 1975 & 36 & & - & 13 & 36.1 \\
\hline Paraguay & 2,647 & 1976 & 5,160 & - & 1.9 & 3,157 & 36.1 \\
\hline Uruguay & 2,782 & 1976 & 492 & 556 & 0.2 & 492 & 88.4 \\
\hline Subtotal & 42,140 & & 15,315 & 15,408 & 0.4 & 9,784 & 63.5 \\
\hline Area I total & 17,935 & & 22,564 & 35,012 & 1.9 & 17,222 & 49.1 \\
\hline Area II total & 77,184 & & 23,338 & 40,042 & 0.5 & 18,602 & 46.5 \\
\hline Area III total & 18,000 & & 1,353 & 3,295 & 0.2 & 854 & 25.9 \\
\hline Area IV total & 49,829 & & 25,839 & 53,897 & 1.1 & 21,980 & 40.8 \\
\hline Area V total & 110,124 & & 150,840 & 242,273 & 2.2 & 91,984 & 38.0 \\
\hline Area VI total & 42,140 & & 15,315 & 15,408 & 0.4 & 9,784 & 63.5 \\
\hline \multicolumn{8}{|c|}{ All the Americas } \\
\hline Grand total & 315,212 & & 239,927 & 389,927 & 1.2 & 160,426 & 41.1 \\
\hline
\end{tabular}

(a) $+50 \%$; (b) $+75 \%$; (c) $+100 \%$; (d) $+200 \%$; (e) estimated, 10 cases.

\section{Summary of the situation by PAHO/WHO areas}

Table 1 shows the number of known patients in American countries or other political units, percentage under surveillance and an estimate of the total number of cases.

\section{PAHO/WHO AREA I}

\subsection{Political units included in Area I}

1.1.1 Countries: Venezuela, Surinam, Guyana, Trinidad \& Tobago, Barbados, Grenada, Bahamas, and Jamaica (Total: 8).

1.1.2 Territories:

1.1 2.1 English: St Lucia, St Vincent, Dominica, Montserrat, St KittsNevis-Anguilla, British Virgin Islands, Antigua, Cayman Islands, Turks \& Caicos Islands, and Bermuda (Total: 11). 
1.1.2.2. French: Guadeloupe, Martinique, French Guiana and St Maarten (1/2) (Total: 4).

1.1.2.3 Dutch (Netherlands Antilles): Curacao, Aruba, Bonaire, St Eustace, Saba and St Maarten (1/2) (Total: 6).

\subsection{Size of the problem}

Leprosy endemicity is highly distinct in this area. Some countries or territories have prevalence rates relatively high (from 9 to 25 per 1,000: French Guiana, Guadeloupe, Martinique and Surinam), however, the multibacillary rates are lower than elsewhere in the area.

With respect to the English-speaking countries and territories, the main leprosy problem is in St Lucia (prevalence rates over 4 per 1,000), Trinidad \& Tobago, Guyana and Grenada (rates over 2 per 1,000).

In Venezuela, the estimated prevalence rate is less than 2 per 1,000 . Over the past 25 years there has been a small reduction of prevalence, perhaps because over $50 \%$ of patients, and similarly in most of the South and Central American countries, are multibacillary cases which, normally, are not released from control. However, case detection rates of all forms of leprosy (incidence) have declined over the same period of time by $75 \%$.

Leprosy prevalence in other countries and territories seems to be low.

\subsection{Operational management, facilities and activities}

In Surinam, Guyana and Jamaica there are well-organized control programmes, integrated into general health care units but with central policy-making and supervisory departments. In Trinidad \& Tobago control actions (case detection and case holding) are the responsibility of a vertical programme but with good co-ordination with general health structures. The organizational aspects of leprosy control in the other English-speaking territories are in the planning stage.

In Venezuela, the service situation is generally well developed, although there are some local variations. The national service for skin diseases has policymaking functions (planning, evaluation) while programme implementation is decentralized and under the responsibility of the state health service.

Standard treatment in all countries and territories is Dapsone, oral or parenteral, but there is a general disposition to adopt combined schedules if Clofazimine, Rifampicin or other drugs are available.

2. PAHO/WHO AREA III

\subsection{Countries included in Area II}

Mexico, Cuba, Dominican Republic and Haiti. 


\subsection{Size of the problem}

The leprosy cases shown in Table 1 have a patching distribution that can be summarized as follows:

(a) Mexico $-70 \%$ of the patients are from the Pacific states (Guanajato, Sinaloa, Najarit).

(b) Cuba - more than half the cases live in the eastern side of the island (Camaguey and South-east provinces).

(c) Dominican Republic - two interesting epidemiological patterns deserve mention, one is the urban distribution of cases (more than $50 \%$ live in Santo Domingo) and the other is that most of the patients are women.

(d) Haiti - the situation is practically unknown. A few cases were detected in only one service, the University Hospital at Port-au-Prince.

\subsection{Operational management, facilities and activities}

In Mexico, policy-making and evaluative functions are centralized in a 'Chronic Skin Diseases Program', and leprosy control implementation is the responsibility of the local health services. Evaluation is assisted by a well kept data registration and information system.

In the Dominican Republic, the leprosy control programme is, by government delegation, the responsibility of a private institution - the Instituto Dermatológico, with policy-making and evaluative functions (there is a written manual of technical and administrative policies). Programmed activities are implemented with the Ministry of Health infrastructure and utilize paramedical personnel to execute the main control actions (screening examinations of contacts and general population for case detection and administration of treatment).

The treatment schedule adopted in Mexico and Haiti is Dapsone monotherapy, generally in low doses $(50-100 \mathrm{mg}$ weekly) but in Cuba and the Dominican Republic the administration of combined treatment (DDS and/or Rifampicine and Clofazimine) is routine.

PAHO/WHO AREA III

\subsection{Countries included in Area III}

Guatemala, Honduras, El Salvador, Costa Rica, Nicaragua, Panama and Belize.

\subsection{Size of the problem}

This area, considered globally, has the lowest prevalence rate in the Americas (excluding the United States and Canada). The main foci are located in the 
Pacific coast (provinces of El Salvador, Honduras and Nicaragua around the Fonseca gulf, Azuero peninsula in Panama). Only two foci are known on the Atlantic coast (Limones in Costa Rica and Bocas del Toro in Panama). The situation in El Salvadore is practically unknown, but more than 200 cases were detected in the past (1958-67). It is interesting to note that in Belize only one case of leprosy was detected, an old lepromatous arrested case.

\subsection{Operational management, facilities and activities}

In three countries (Honduras, Costa Rica and Panama) there are well organized control programmes, integrated into the general health structure (with social security in Costa Rica). In Nicaragua and Guatemala, there are practically no control activities, except the care of a few in-patients (leprosaria). In El Salvador a few patients (not officially notified) are treated in the dermatological ward of Rosado Hospital in San Salvador.

With the exception of Costa Rica that has adopted combined regimens and parenteral Dapsone, the rule is DDS monotherapy.

The need of training and motivation in the area is evident.

\section{PAHO/WHO AREA IV}

\subsection{Countries included in Area IV}

Colombia, Ecuador, Peru and Bolivia.

\subsection{Size of the problem}

The most important problem is Colombia with around 2,000 cases under treatment. The main focus (70\% of the cases) lives in the departments of the oriental branches of the Andean 'Cordillera', that is, some important foci are in altitudes above $2,000 \mathrm{~m}$ (6,000 feet). In Ecuador most of the detected cases came from the Pacific coast provinces (Guayas, Los Rios and El Oro) and very few cases from the 'Sierra' or Andean 'Cordillera'. In Peru more than $80 \%$ of the cases are infected in the Amazon rain forest, mainly on the Ucayali river and its tributaries.

In Bolivia, leprosy apparently does not propagate in the Andean highlands, but the situation is serious in the Santa Cruz and Chuquisaca departments (south-east of the country) on the slopes of the Andes and the far north-east the Amazon basin.

An intensive survey (Vallegrande province, Santa Cruz department 32,000 inhabitants) has shown a point prevalence of 14 per 1,000 (1974). 


\subsection{Operational management, facilities and activities}

Colombia, since 1958, has a structured vertical programme implemented by 32 regional units. By decision of the Ministry of Health all facilities and personnel were decentralized (October 1977) to the Department of Health Services, and a policy of integration is to be implemented in the next years. The first one will be Santander and a plan for this aim was drafted.

About 4,000 cases are treated as in-patients (leprosaria).

Ecuador, since 1975, has integrated its leprosy control activities into the general public health services. The results are satisfactory in Guyas province where a well-developed health infrastructure exists, but not in other endemic areas like Los Rios, Bolivar and El Oro where the health centres or posts are not staffed or managed as expected.

In Peru, leprosy control activities are integrated into the health service of the Amazon departments (Loreto and San Martin), The main structure for primary medical care of the scattered population is the 'Posta Sanitaria' staffed with only one auxiliary health worker. Most of these auxiliaries are trained for diagnosis of suspicious leprosy cases and administration of treatment.

Leprosy control in Bolivia is centered around four focal points.

(a) Jorochito Hospital near Santa Cruz city - 90 beds (for tropical diseases in general) and out-patients ward, but no field activities.

(b) Vallegrande Province (Santa Cruz Department) is a field station of CENETROP (Centro Nacional de Enfermedádes Tropicales) where a comprehensive health care programme is being implemented and leprosy control is an important component.

(c) Monteagudo Hospital and out-patient clinic. There are 15 beds (only for leprosy patients) but the main activities (case detection and treatment delivery) are implemented in the foci by travelling teams (doctor and auxiliary personnel).

(d) Beni Department (Amazon basin) - patients are cared for in a dermatological ward in Trinidad (Department capital- and those who live far from this centre are visited (no more than once a year) by personnel from the haemorrhagic fever programme which is headed by the chief of leprosy control.

Treatment policy is Dapsone monotherapy but the Ministry of Health is aware of the need for combined regimens.

\section{PAHO/WHO AREA V}

\subsection{Country included in Area $V$}

Brasil. 


\subsection{Size of the problem}

More than $60 \%$ of the known leprosy cases in the Americas are from Brazil, but as observed in almost all other American countries, the geographical distribution of the endemia is uneven. A breakdown of the prevalence rates for the region (December 1975) is:

$\begin{array}{lc} & \text { per } 1,000 \\ \text { Amazon } & 2.94 \\ \text { North-east } & 0.30 \\ \text { South-east } & 1.68 \\ \text { Midwest } & 2.01 \\ \text { South } & 0.97\end{array}$

The Amazon region has $6.9 \%$ of the general population of the country and 15.6 of the registered cases, while for the south-east region the figures are $42.2 \%$ and $55.1 \%$ respectively.

In 1975 the incidence of detected new cases was 8.68 per 100,000 inhabitants $(9,300$ patients) and $48.7 \%$ lepromatous and borderline forms.

\subsection{Operational management, facilities and activities}

All activities for leprosy control are integrated into the state general health services, but policy-making and general evaluation is centralized in the Ministry of Health (Division of Sanitary Dermatology).

In Brazil there are 29 leprosaria or colonies with 15,689 in-patients (December 1975).

General treatment policies include Dapsone monotherapy (oral or repository) and particularly in the last year combined regimens (Rifampicine, DDS and Clofazimine).

Recently the federal government decided to formulate and implement a special leprosy control programme under the responsibility of the sanitary dermatology division to cope with the problem of Acre State and the Amazon territories and Para State bordering the transamazon highway.

6. PAHO/WHO AREA VI

\subsection{Countries included in Area VI}

Argentina, Uruguay, Paraguay and Chile.

\subsection{Size of the problem}

Argentina: The known cases are concentrated in the north-eastern provinces and also in the metropolitan area of 'Great Buenos Aires' where about $70 \%$ of the cases are not autochthonous but immigrated from hyperendemic areas. 
Paraguay has the highest prevalence in South America (estimated at 3.3 per $1,000)$, and almost all cases detected in the eastern provinces and the capital, Asuncion.

In Uruguay the only information available shows that there are 514 leprosy patients under treatment in Montevideo.

Chile presents a unique epidemological situation - no cases (except a few imported from Argentina) and a high prevalence $(30$ per 1,000) in Easter Island, about 5,000 miles from the Chilean Pacific Coast, and with a population ethnically polynesian.

\subsection{Operational management, facilities and activities}

Leprosy control in Argentina was integrated into the general health services in 1969 , a policy that could not be implemented due to many difficulties encountered in co-ordinating the field work.

The Ministry of Health has recently decided to formulate a new programme with $\mathrm{PAHO} / \mathrm{WHO}$ assistance. The general strategy will be the implementation of a vertical specialized control programme, taking full advantage of existing resources and structures which have proved their usefulness in detecting and treating leprosy cases (about $25 \%$ of the patients are being treated by private doctors).

In Paraguay there is a well planned and supervised control programme which utilizes paramedical personnel for case detection (screening examination), patient care and emphasizes close co-ordination with the general health structure.

An important source of funds for programme implementation came from ILEP (German Leprosy Relief Association).

Uruguay is just starting to evaluate its problem; many patients are now being treated and a request was presented to $\mathrm{PAHO} / \mathrm{WHO}$ to assist in the formulation of a programme.

In Chile the few patients detected in Easter Island are under treatment. A survey of the total population $(1,200$ inhabitants) will be made in May 1978 by a PAHO/WHO adviser and control measures will be recommended.

In Area VI there are 5 leprosaria (Argentina, 1,048 patients; Paraguay, about 350 patients).

Treatment is mainly Dapsone monotherapy, except in Argentina where combined regimens are being planned.

\section{CONCLUSIONS AND RECOMMENDATIONS}

\section{1}

Leprosy in the Americas could be considered as 'median prevalence'. Nevertheless, there are some limited foci where transmission seems to be comparable with some African or Asian foci. 
In many American countries the leprosy problem does not have priority related to the size of the problem and relative public health importance.

\section{3}

One of the main constraints to implementation of control programmes is a general shortage of funding sources coupled with deficient training (and motivation) of the personnel.

\section{4}

The financial assistance offered by the Japanese shipbuilding industry will be welcome by all interested countries and will help to remove many of the observed constraints if used judiciously.

The general stategy proposed for utilization of JSIF funds through WHO is:

7.4.1 Reinforcement and upgrading of training and training capability. Priority must be assigned to countries of fewer resources and more important problems.

(a) Some funds could be used to facilitate mobility of trainees and staff in field work demonstration at CEPIALET (PAHO/WHO Panamerican Center for Research and Training in Leprosy and Tropical Diseases Caracas, Venezuela.)

(b) Awarding of fellowships for training abroad (CEPIALET).

(c) Assistance in national courses or seminars.

(d) Assistance for regional or subregional workshops on selected matters of control policies.

(e) Funding of STC expenses for educational technology for CEPIALET.

7.4.2 Funding of advisory services (PAHO/WHO STC) for programme formulation.

7.4.3 Assistance to selected countries or areas in implementation of field work (transportation and subsistence expenses).

7.4.4 Supplies and equipment - mainly drugs for combined regimens (Rifampicin, Clofazimine, DADDS).

7.4.5 Some allocations to reinforce PAHO/WHO duty travel expenses (regular staff).

The annexed tentative budget (1978-81) was drafted taking into account this proposed strategy. 